\title{
Electrochemical Determination of Vitamin A Based on a Novel Nanoalloy Modified Carbon Paste Electrode
}

\author{
Xiaoshun Lv", Jie Zhao, Xue Dong, Hongshuai Tian, Shufang Qi, Yuchan Jiang and Yiling Ping \\ Department of Obstetrics and Gynecology, The Children \& Women's Healthcare of Laiwu City, \\ Laiwu City, Shandong, 271100, P.R. China \\ *E-mail: lvxiaoshun98@126.com
}

doi: $10.20964 / 2017.09 .23$

Received: 16 May 2017 / Accepted: 5 July 2017 / Published: 13 August 2017

\begin{abstract}
Preeclampsia has been proposed to occur after a partial breakdown in tolerance during fetal development due to maternal immune maladaptation. A few of the immunomodulatory features of the hormonal vitamin A system have the potential for enhancing immunity during pregnancy. This study proposed a new carbon paste electrode (CPE) that was modified using a nanoalloy (Pt:Co) roomtemperature ionic liquid (RTIL) as an extremely sensitive sensor for the voltammetric detection of vitamin A in food specimens. The proposed sensor was found to be effective for vitamin A electrooxidation in aqueous solutions. As an extremely sensitive electrochemical technique, square-wave voltammetry (SWV) was used for the detection of vitamin A (in submicromolar amounts). The linear response range and detection limit were found to be $0.1 \mu \mathrm{M}$ to $100 \mu \mathrm{M}$ and $0.04 \mu \mathrm{M}$, respectively. The developed sensor can be used for the detection of vitamin A in tablet and food specimens.
\end{abstract}

Keywords: Vitamin A; Ionic liquid; Nanoalloy; Electrochemical determination; Square wave voltammetry

\section{FULL TEXT}

(C) 2017 The Authors. Published by ESG (www.electrochemsci.org). This article is an open access article distributed under the terms and conditions of the Creative Commons Attribution license (http://creativecommons.org/licenses/by/4.0/). 